\title{
Koşuyu Etkileyen Biyomekaniksel Faktörler
}

\author{
Biomechanical Factors Affecting Running \\ Gül Öznur KARABIÇAK ${ }^{1 \text { A,B,C,D,E,F,G }}$ \\ ${ }^{1}$ Adnan Menderes Üniversitesi Sağlık Bilimleri Fakültesi Fizyoterapi ve Rehabilitasyon Bölümü, Aydın, Türkiye
}

ÖZ

\begin{abstract}
Toplumda aerobik egzersizin sağlıklı yaşam ve yaşam kalitesine faydalarıyla ilgili bilincin artmasıyla birlikte tempolu yürüyüş ve koşu, toplumda giderek popüler hale gelen sporlar arasında yer almaya başlamıştır. Bu egzersizlere katılım arttıkça koşu ile ilgili hem akut hem kronik yaralanmaların insidansında doğal bir artış görülmektedir. Yaralanmaların hem önlenmesi hem de etkin bir şekilde tedavi edilebilmesi amaciyla yürüyüşün ve koşunun biyomekaniklerinin doğru bir șekilde anlaşılması önem taşır. Uygun koşu biyomekanikleri, kinetik halkanın tüm komponentlerinin senkronize hareketlerini içerir. Ayak; zemine uyum, denge ve propriosepsiyon ile birlikte itme fazı için gerekli itmeyi sağlar. Gövde ve pelvisteki uygun olmayan dizilim, vücut mekaniklerini etkiler, dolayısıyla yaralanmalara neden olur. Bu yüzden koşu boyunca tüm kinetik zincire etkiyen biyomekaniklerin anlaşılması ve dikkate alınması gereklidir. Bu yazıda kısaca yürüyüş ve koşu arasındaki biyomekaniksel farklılıklara ve koşma sırasında alt ekstremitede meydana gelen biyomekaniksel fazlara değinilecektir, sonrasında koşunun kinetik zincire etkisinden bahsedilecektir.
\end{abstract}

Anahtar Kelimeler: Koşu, Yürüyüş, Yaralanma, Kinematik, Kinetik

\section{ABSTRACT}

With the increasing awareness of the benefits of aerobic exercise on healthy lifestyle and quality of life in society, jogging and running are becoming increasingly popular in the community. As participation in these exercises increases, there is a natural increase in the incidence of both acute and chronic injuries related to running. An accurate understanding of the biomechanics of walking and running is important in order to prevent and effectively treat injuries. A proper running gait biomechanics includes the synchronized motion of all components of the kinetic chain. The foot provides adjustment to the ground, balance, proprioception and propulsion needed for take off. Abnormal alignment of the pelvis and the trunk affects body mechanics, consequently cause injuries. Therefore it's essential to understand the biomechanical effects on all the kinetic chain during running. This article will briefly address the biomechanical differences between walking and running, afterwards, the biomechanical phases that occur in the lower extremity during running will be discussed.

Key words: Running, Gait, İnjury, Kinetics, Kinematics

\section{GíRiș}

\section{KOŞU VE YÜRÜYÜS ARASINDAKİ TEMEL FARKLAR}

Normal yürüyüş gibi koşu da duruş ve sallanma olmak üzere temel iki fazdan oluşur. Yürüyüşte duruş fazının hem başında hem de sonunda yer alan her iki ekstremitenin yerle temasta olduğu çift destek periyodu koşuda kaybolur. Koşuda yalnızca tek ayak yerle temastadır, ayrıca iki adet sallanma fazının başı ve sonunda süzülme fazı olarak adlandırılan ve her iki ekstremitenin yerle temasının olmadığı bir periyod yer alır (1). Bu değişiklik, duruş fazının süresinin kısalmasına, sallanma fazının ise artmasına neden olur. Yürüyüşün aksine öne

Sorumlu Yazar: Gül Öznur KARABIÇAK

Adnan Menderes Üniversitesi Sağlık Bilimleri Fakültesi Fizyoterapi ve Rehabilitasyon Bölümü, Aydın, Türkive

guloznur@gmail.com

Geliș Tarihi: 16.08.2019 - Kabul Tarihi: 14.06.2020

Yazar Katkıları: A) Fikir/Kavram, B) Tasarım, C) Veri Toplama ve/veya İşleme, D) Analiz ve/veya Yorum, E) Literatür

Taraması, F) Makale Yazımı, G) Eleştirel İnceleme 
doğru hareket için gerekli olan güç, yerdeki bacaktan değil öne doğru salınan bacak ve koldan sağlanır $(1,2)$.

Koşucuların, yürüyüş yapanlara göre eklem ve kaslarına binen yük çok daha fazladır. Koşu ile ayak bileği, diz ve kalça eklem hareket alanında daha fazla artış kaydedilir. Lumbal bölge ve pelvis gibi diğer yapılar da bu durumdan etkilenir ve eklem hareket açıklıkları artar. $\mathrm{Bu}$ durum ise alt ekstremite yaralanma riskini artırır (2).

Hızdaki artış artan adım uzunluğunu takip eden kadanstaki artış ile sağlanır. Hız arttıkça periyodlar arası geçiş süresi sıklaşır ve periyod süresi kısalır. Alt ekstremitenin hızı artar. Hareket kontrolü için gerekli eksentrik kasılma sebebiyle enerji harcaması artar. Bu durum koşulabilecek mesafenin kısalması ile sonuçlanır. Bu ihtiyaçları sağlamak amacıyla daha fazla normal eklem hareketi ve kas gücü gereklidir.

Yürüme ve koşmada ağırlık merkezi sinüzodial bir eğri halinde hareket eder, fakat koşmada vücut tüm periyod boyunca öne doğru eğilmiş bir şekilde hareket eder. Hız arttıkça alt ekstremite eklemleri eklem hareket açıklığını artırarak ağırlık merkezinin vertikal yönde yer değişimini azaltmaya çalışır. Bu yüzden daha hızlı koşucular daha fazla esneklik ve eksentrik kas kuvvetine ihtiyaç duyarlar (2).

\section{KOŞUDA YER ALAN PERIYYODLAR}

Koşu, duruş ve süzülme fazı olmak üzere 2 fazdan oluşur. Koşu esnasında çift destek periyodu hız ile beraber kaybolur. Ayağın yer ile temasının devam ettiği duruş fazı sonrası her iki ekstremitenin yerden temasının kesildiği süzülme fazı ile devam eder.

\subsection{Duruş Fazı}

Koşuda duruş fazı ayak teması ile başlar, orta duruş ve itme ile devam eder. Ayak teması sonrasında; kas, tendon, kemik ve tüm alt ekstremite yere iniş esnasında oluşan şoku absorbe etme fonksiyonu görür (3). mevcuttur:

Koşuda farklı ilk ayak temasları oluşabilir. Temel olarak üç tip ilk ayak teması

Topuk vuruşu (Heel strike): Genellikle topuk laterali ve supinasyon ile başlar. Ayakkab1 kullanan koşucularda sıklıkla kullanılan tiptir.

Orta ayak vuruşu (Midstrike): Ayağın bütünü ile ilk temas söz konusudur. Çıplak ayak koşucuları tarafından sıklıkla tercih edilir.

Önayak vuruşu (Forefoot strike): Koşuda hızın yüksek olduğu zamanlarda kullanılır. Bunun dışında sıklıkla supinasyonda koşanlar tarafindan tercih edilir. Bazen topuk teması duruş fazı boyunca gerçekleşmez.

İlk temas sonrası, orta duruş fazında ise ayak bileğindeki dorsifleksiyonla birlikte kalça ve dizde fleksiyon hareketi meydana gelir. Böylece yere iniş esnasında oluşan stresler tüm alt ekstremite tarafından absorbe edilir. Ayakta meydana gelen bu farklı ilk temas çeşitleri kalça ve dizde meydana gelen fleksiyon açısını ve dolayısıyla yüklenmenin miktarını değiştirmektedir.

Koşuda da yürümede olduğu gibi duruş fazında, subtalar pronasyon ve supinasyon hareketleri meydana gelir. Yere ilk temas esnasında hareketler ayağın pronasyonuna neden olan 
subtalar eklem tarafindan fasilite edilir. Ayrıca plantar fasya da gerilerek ayak tabanının genişlemesini sağlar (3).

Yürüyüşün pronasyon fazı, eksentrik kas kontraksiyonu ile tamamlanarak eklemlerde şok absorbsiyonu sağlanır. Supinasyon fazı ise özellikle gluteal konsentrik kas kontraksiyonunu içerir, hızlanma ve itmeyi sağlar.

Gastroknemius ve Rectus Femoris kasları süzülme sonrası yere inme sırasında oluşan enerji etkisini distalden proksimale iletir. Böylece iniş anında oluşan etki ve şokun azaltılması, tüm alt ekstremiteye dağıtılması sağlanır. Yapılan son çalışmalar bu yükün dağıtılması ve şok absorbsiyonunun koşuya bağlı kas yorgunluğu ile değişmediğini göstermektedir (3).

Orta duruş sonrası ayaktaki pronasyon, supinasyon hareketine dönüşerek itme fazını başlatır. Duruş fazının devamında itme fazında hamstring kasları kasılarak kısalır. Aşil tendonu, soleus kaslarının kontraksiyon ve çekişi ile ayak bileği plantar fleksiyonu sağlanır ve itme hareketi oluşur. Ardından süzülme fazı başlar.

\subsection{Süzülme (Uçuş) Fazı}

Her iki ayağın yerle temasının olmadığı fazdır. Ayak yerden temasını kestikten sonra en aktif kaslar Rektus Femoris ve Tibialis Anterior kaslarıdır. Hamstringler ve kalça ekstansor kasları süzülme fazının sonunda aktifleşir. Hamstringler, Gastrosoleus kompleksi ve kalça ekstansor kasları süzülme fazı sonundan duruş fazına dek aktivite gösterir (4).

Süzülme fazı, Psoas ve diğer pelvik kasların kontraksiyonu ile ipsilateral pelvisin öne rotasyonu ve kalça fleksiyonunu içerir. Rektus Femoris kası orta süzülme fazında aktiftir. Quadriseps süzülme fazı sonunda aktifleşir. Ardından ayak yere doğru yaklaşarak duruş fazını başlatır. Aynı anda karşı ayak duruş fazını bitirmek üzeredir $(2,4)$.

\section{KOŞU ve KINETIK ZINCIR}

Koşu esnasında ayak, ayak bileği, diz, kalça, pelvis, gövde ve üst ekstremitenin her biri aktif rol alır. Koşu ile birlikte artan alt ekstremite hareketlerine pelvis, lumbal bölge eşlik eder. Pelvis, sakrum ve lumbal vertebralar ekstremitelere koşu için gerekli stabiliteyi sağlar. Pelvis koşu siklusu boyunca rotasyonel, antero-posterior ve medio-lateral düzlemlerde simetrik bir hareket paterni izler. Artmış anterior pelvik tilt, aşırı lateral tilt ya da asimetrik kalça hareketleri gibi pelvik halkayı içeren biyomekanik anomaliler koşucularda meydana gelen pek çok yaralanma ile ilişkilidir $(2,3,5)$.

Koşu esnasında yalnızca alt ekstremite değil, tüm vücut rol alır. Kalça ve alt ekstremite hareketleri harekete izin vermesi ve yaralanmaların önlenmesi için kuvvetli ve stabil bir gövdeye ihtiyaç duyar. Üst gövdenin dinamik komponentleri kostalar, sternum, torasik ve lumbar vertebraları içeren ligament ve kaslardan oluşur. Abdominal, paraspinal, gluteal ve pelvik taban kaslarını içeren gövde kasları koşu ile meydana gelen etki kuvvetlerinin absorbe edilmesi ve dağıtılmasında; bununla birlikte koşu sırasında gövde hareketlerinin etkin ve kontrollü bir şekilde devamlılığının sağlanmasında rol alır $(2,6)$. Artan hızla beraber elit sporcularda rekreasyonel koşuculara göre daha stabil bir gövde çalışmalarda dikkat çekmektedir. $\mathrm{Bu}$ yüzden gövde stabilitesinin koşucularda üstünde durulması ve kuvvetlendirilmesi yaralanmaları önlemesinde önemli bir yer tutar (7). Üst ekstremitenin koşu esnasında denge ve stabilitenin sağlanmasında önemli bir rolü vardır. Kural olarak her bir kol 
süzülme fazında karşı bacağın hareketini dengeler. Ayrıca Hamner ve ark tarafindan yapılan çalışmada duruş fazının itme kısmında vertikal açısal momentumun etkin bir şekilde dengelenmesinde rolü olduğu gösterilmiştir (8).

\section{Koşu Ayakkabılarının Biyomekanik Etkileri}

İlk temas sırasında ön ayak vuruşu yapanlarda meydana gelen diz fleksiyonu arka ayak vuruşu yapanlardan daha fazladır. Ön-Orta ayak vuruşu ile ilk temas kinematikleri karşılaştırıldığında ön ayak vuruşu ile koşanlarda duruş fazında oluşan diz fleksiyonu daha fazladır. Bu nedenle, arka ayak ile ilk temas edenlerde vertikal yüklenme daha fazla oluşmaktadır (9). 434 rekreasyonel koşucu üzerinde yapılan bir araştırmada sporcuların yaklaşık \%90'ının arka ayak kullanarak ilk teması gerçekleştirdiği ve standart spor ayakkabısında arka ayakla ilk temasın daha sık tercih edilirken $(\% 70)$ minimalist ayakkabı ile 9,2 kat daha fazla önayak vuruşu tercih edildiği saptanmıştır (10). Bu çalışma sadece koşu şeklinin değil zeminin de koşudaki önemini vurgulamaktadır. Ayrıca rekreasyonel sporcularda arka ayak temasının koşuda çok daha sık kullanılması aslında yaralanmaların bu grupta sık görülme nedenini de açıklamaktadır.

Duruş fazı topuk teması ile başladığında dorsifleksiyon pozisyonunda olan ayak-ayak bileği eklemi daha serttir ve önayak ya da orta ayak vuruşunda olduğu gibi çarpma kuvvetinin etkisini diğer eklemlere dağıtamaz. Bu durum oluşan etki kuvvetinin ayak bileği dorsifleksiyonu ve diz fleksiyonu ile kinetik rotasyonel enerji halkasına transfer edilememesinden kaynaklanır.

Farklı ayak basışlarının kullanımı alışkanlığa bağlı gelişir. Birbiri üzerine olan yaralanmaya neden olan risk faktörleri tanımlanmış olsa bile alışılmış koşu stillerinin değiştirilmesi zor ve faydalı değildir. Bu durumda kişinin doğal halinde yüklenme altında kalan kas, ligament gibi yumuşak dokularını kuvvetlendirmek daha iyi bir seçenek olarak görünmektedir $(11,12)$.

Koşuda yürüyüșe göre ayağa üç kat daha fazla yük binmektedir. Bu yüzden ayağ korumak ve belli yüklenmeler altında ayakta oluşan yükleri nötralize ederek aslında yaralanmaları önlemek amacıyla ayakkabılar kullanılmakta ve tasarlanmaktadır.

Çıplak ayakla koşu sık kullanılmasına rağmen bu koşu ile ilgili yapılmış uzun dönem çalışmaların olmayışı sonuçların doğru bir şekilde değerlendirilmesini zorlaştırmaktadır. $\mathrm{Bu}$ yüzden motor performans üzerine etkileri belirsizdir (13).

Gelişen teknoloji ile birlikte pek çok ayakkabı çeşidinin kullanımı dikkat çekmektedir. Koşuda kullanılan ayakkabılar; geleneksel, rocker bar ve minimalist tarz olarak kabaca sınıflanabilir. Rocker bar içeren koşu ayakkabıları prensip olarak itme fazını kolaylaştırarak koşu ekonomisi sağlaması amacıyla aşil tendon yaralanması sonrası kullanılır. Fakat yapılan araştırmalar Rocker tabanlıklı ayakkabıların aşil tendonuna binen yükü azaltmakla birlikte kalça ve dizde overuse tipi tekrarlayan yaralanmalara neden olabileceği yönündedir (14).

Minimalist ayakkabılar son dönemde çıplak ayak koşusunu taklit ederek hem koşu ekonomisi sağladığı hem de koşu kinematiklerinde çıplak ayak ile koşu etkisi yarattığı iddiası ile kullanılmaktadır. Yapılan çalışmalarda minimalist ayakkabıların basış açılarını azalttığı; fakat basış paternini ya da vertikal yüklenmeyi değiştirmediğini göstermektedir. Ayrıca bu ayakkabıların geleneksel ayakkabılara göre daha fazla enerji harcamasına neden olduğunu gösteren çalışmalar literatürde göze çarpmaktadır (15-17). 
Ayakkabıların koşu esnasında oluşan ve koşucularda yaralanmayı önleyen adaptif pronasyonu engellediğine yönelik çalışmalar mevcuttur. Bununla birlikte ayakkabı kullanımı duruş fazında meydana gelen ve şokların adaptasyonunu sağlayan kalça ve diz fleksiyonunu azaltarak yaralanma riskini artırabilir (18).

\section{SONUÇ}

Koşu da yürüyüşte olduğu gibi birbirini tekrarlayan ayaktaki pronasyon ve supinasyon hareketinden oluşur. Koşu esnasında meydana gelen farklı ilk temas türleri yaralanmalar ile ilişkilidir; fakat, ilk teması değiştirmek yerine mevcut duruma uyum sağlayarak yaralanmaya meyilli yumuşak dokuları kuvvetlendirmek çok daha yapıcı bir yaklaşım olarak ortaya çıkmaktadır. Koşu biyomekanisinde tüm kinetik zincirin birbiri ile olan ilişkisi, alt ekstremitenin yeterli eklem hareket kabiliyeti ve esnekliği kadar büyük önem taşımaktadır. Bu yüzden kinetik zincirde meydana gelen bir patomekani tüm koşu biyomekanisini etkiler. Özellikle gövde stabilitesinin koşucularda yaralanmanın önlenmesi ve performansın artırılması amacıyla önemi literatürde vurgulanmaktadır.

\section{Çıkar Çatışması}

Yazarlar arasında çıkar çatışması yoktur.

\section{KAYNAKLAR}

1. Alsancak, S. (2015). Yürüyüş terminolojisi. Ankara Sağlık Hizmetleri Derg, 14(2), 1-5.

2. Nicola, T. L., \& Jewison, D. J. (2012). The anatomy and biomechanics of running. Clin Sports Med, 31(2), 187-201.

3. Dugan, S. A., \& Bhat, K. P. (2005). Biomechanics and analysis of running gait. Phys Med Rehabil Clin N Am, 16(3), 603-621.

4. Tom, N., \& Novacheck, T. (1998). Review paper: The biomechanics of running. Gait Posture, 7, 77-95.

5. Chumanov, E. S., Heiderscheit, B. C., \& Thelen, D.G. (2007). The effect of speed and influence of individual muscles on hamstring mechanics during the swing phase of sprinting. J Biomech, 40(16), 3555-3562.

6. Elliott, B. C., \& Blanksby, B.A. (1979). A biomechanical analysis of the male jogging action. J Hum Mov Stud, 5, 42-51.

7. Preece, S. J., Mason, D., \& Bramah, C. (2016). How do elite endurance runners alter movements of the spine and pelvis as running speed increases? Gait Posture. 46, 132134.

8. Hamner, S. R., Seth, A., \& Delp, S. L. (2010). Muscle contributions to propulsion and support during running. J Biomech, 43(14), 2709-2716.

9. Almeida, M.O., Davis, I.S., \& Lopes, A.D. (2015). Biomechanical differences of footstrike patterns during running: A systematic review with meta-analysis. J Orthop Sport Phys Ther, 45(10), 738-755.

10. Cheung, R. T. H., Wong, R. Y. L., Chung, T. K. W., Choi, R. T., Leung, W. W. Y., \& Shek, D. H. Y. (2017). Relationship between foot strike pattern, running speed, and footwear condition in recreational distance runners. Sport Biomech, 16(2), 238-247. 
11. Boyer, E. R., \& Derrick, T. R. (2018). Lower extremity joint loads in habitual rearfoot and $\mathrm{mid} /$ forefoot strike runners with normal and shortened stride lengths. Journal of sports sciences, 36(5), 499-505.

12. Miller, R. H., Edwards, W. B., Brandon, S. C. E., Morton, A. M., \& Deluzio, K. J. (2014). Why don't most runners get knee osteoarthritis? a case for per-unit-distance loads. Med Sci Sports Exerc, 46(3), 572-579.

13. Hollander, K., Heidt, C., Van Der Zwaard, B. C., Braumann, K. M., \& Zech, A. (2017). Long-term effects of habitual barefoot running and walking: A systematic review. Med Sci Sports Exerc, 49(4), 752-762.

14. Sobhani, S., van den Heuvel, E. R., Dekker, R., Postema, K., Kluitenberg, B., Bredeweg, S. W., \& Hijmans, J. M. (2017). Biomechanics of running with rocker shoes. Journal of science and medicine in sport, 20(1), 38-44.

15. Chen TLW, Sze LKY, Davis IS, Cheung RTH. (2016). Effects of training in minimalist shoes on the intrinsic and extrinsic foot muscle volume. Clin Biomech, 36, 8-13.

16. Cochrum, R. G., Connors, R. T., Coons, J. M., Fuller, D. K., Morgan, D. W., \& Caputo, J. L. (2017). Comparison of Running Economy Values while wearing no shoes, minimal shoes, and normal running shoes. J Strength Cond Res, 31(3), 595-601.

17. Rice, H. M., Jamison, S. T., \& Davis, I. S. (2016). Footwear Matters: Influence of footwear and foot strike on load rates during running. Med Sci Sports Exerc, 48(12) 2462-2468.

18. Francis, P., Ledingham, J., Clarke, S., Collins, D. J., \& Jakeman, P. (2016). A comparison of stride length and lower extremity kinematics during barefoot and shod running in well trained distance runners. J Sport Sci Med, 15(3), 417-423. 